\title{
PROGRAMAS EDUCATIVOS NA TV
}

\section{Conteúdo pedagógico adequado à narrativa televisual e à fantasia, para uma programação infantil divertida e inteligente}

Acredita-se que grande parte das crianças e dos adolescentes brasileiros, por viver em famílias com renda per capita inferior a meio salário mínimo (19,8 milhões, segundo dados da Unicef e da Fundação IBGE) 1 , tem como fonte principal de divertimento e informação a programação gratuita das emissoras de televisão aberta.

Em 1990, o Estatuto da Criança e do Adolescente indicava atendimento prioritário às necessidades educativas específicas desse seguimento por meio de programação veiculada pelas emissoras de rádio e televisão. Diz o artigo 76: "As emissoras de rádio e televisão somente exibirão, no horário recomendado para o público infanto-juvenil, programas com finalidades educativas, artísticas, culturais e informativas"2.

Considerando programa educativo aquele produzido em função de uma intencionalidade educativa, seria possível sua exibição pela televisão fora de circuitos fechados, para público não adulto? Para ser apreendido, dependeria de uma complementação professor-sala de aula? Esse tipo de programação seria compatível com o interesse maior das emissoras comerciais de atrair público, conquistar e manter audiêncía? O público infanto-juvenil não recusaria uma programação que prioriza a função educativa?
O desempenho da função educativa pelas emissoras de televisão comerciais todas elas concessões públicas - passou a ser cobrado oficialmente pelo decreto 236 , de 28 de fevereiro de 1967. Instituiu-se a obrigatoriedade de transmissão diária de programas educativos. Definiu-se programa educativo em televisão aquele restrito à "transmissão de aulas, conferências, palestras e debates". Delinearam-se as características do público-alvo, excluindo as crianças. Argumentava-se: "podemos testar a aptidão didática da TV para ensinar a adolescentes e adultos que não podem mais se matricular na rede regular, e que estão hoje premidos no mercado de trabalho pelas exigências de habilitação educacional'’3.

Esse esforço em fazer a televisão funcionar educacionalmente seguindo "modos sedimentados", como observa Braga, "corresponde a usar as linguagens do livro e da sala de aula para fazer televisão ou rádio educativo, por exemplo. Neste molde, as aulas parecem não corresponder às expectativas de leitura dos espectadores e, portanto,

\section{A AUTORA}

\section{Vânia Lúcia Quintão Carneiro}

Professora Doutora da Faculdade de Educação da Universidade de Brasilia-UnB. Pesquisadora na área de Televisão e Educação. $E$-mail: valc@ @uarany.unb.br 
não conseguem facilmente resultados positivos. São cansativas, monótonas" 4 . White e Thomas, em estudo sobre experiências educacionais pela $\mathrm{TV}$, constataram a "falácia da idéia de que, se a informação fosse apresentada de maneira clara e séria, os ouvintes seriam convencidos de suas vantagens óbvias, através de argumentos racionais". Acrescentam que hoje há a percepção de que os programas "devem usar dramatizações, humor, um ritmo rápido e um toque pessoal" 5.

Carneiro observou que a concepção de programa educativo mais conhecida caracteriza-se pela seriedade, pela negação da função de entreter e de atrair o público ${ }^{6}$. Enquadra-se no modelo clássico de filme pedagógico, que de acordo com estudos de Jacquinot $^{7}$ atende às exigências de uma intenção didática, ignorando uma formulação audiovisual. Subordina-se às necessidades não de uma narrativa, mas de uma explicação lógico-abstrata. $\mathrm{O}$ mundo da ficção que caracteriza o universo dos filmes de entretenimento é excluído. Em seu lugar se fazem presentes o mundo mundano/real e os mundos pedagógicos: o da escola e o do especialista. No entanto, até que ponto a predominância dessa concepção de programa educativo, identificada como gênero escolar, não justifica a desobrigação dos meios de comunicação de cumprir com as exigências de atendimento a finalidades educativas?

Em 1991, o tempo obrigatório de exibição de programação educativa pela televi- são brasileira foi reduzido. De cinco horas semanais passou a dois programas de vinte minutos aos sábados e domingos, por meio de acordo feito entre emissoras através da Associação Brasileira de Emissoras de Rádio e Televisão - ABERT $^{8}$ e do Ministério da Educação - MEC. Soares afirma que esta redução foi feita em consonância com o ideário que considera "nefasta e inadequada qualquer idéia de compromisso sério e formal entre Comunicação Social e Educação. A Comunicação Social serve para distrair, informar e vender (...)! Sua linguagem e seu timing são impróprios para o exercício sempre tedioso - do ensino!"”.

\section{PÚBLICO INFANTIL E CAPACIDADE DE APRENDER}

As crianças, segundo pesquisa de Schramm, eram mais intolerantes que seus pais em relação à proposta de assistir a programas educativos em suas casas. Mas apesar da não-aceitação da programação educativa, pois elas buscam sempre a diversão na televisão, não recusavam o aprendizado proporcionado pela programação de entretenimento. Pelo contrário, gostavam de programas que proporcionassem incidental learning. Aprendiam com a programação sem intenção educativa. Este estudo reconheceu a televisão como fonte de fantasia, informação e formação ${ }^{10}$.

4. BRAGA. J. L. Meios de comunicação e linguagens: a questão educacional e a interatividade. Textos de Comunicação e Cultura. Salvador: Faculdade de Comunicação da UBBA, n. 34, 1995. p. 32-34.

5. WHITE, R. A., THOMAS, P. Transmissão educativa. Comunicação \& Educação. São Paulo: CCA-ECA-USP/Moderna, n. 5 , jan./abr. 1996. p. 50-61.

6. CARNEIRO, V. L. Q. O educativo como entretenimento na TV Cultura: Castelo Rá-Tim-Bum, um estudo de caso. São Paulo: Faculdade de Educação - USP, 1997. 198p. (Tese de Doutorado.)

7. JACQUINOT, G. Image et Pédagogie (Imagem e Pedagogia). [s.l.]: Presses Universitaires de France, 1977.

8. ABERT. Iniciando uma nova jornada. Brasília, n. 76 , set. 1992. p. 19.

9. SOARES, I. O. A televisão e as prioridades da educação. Comunicação \& Educação. São Paulo: CCA-ECA-USP/Moderna, n. 6, maio/ago. 1996. p. 22-28.

10. SCHRAMM, W. et al. Television in the lives of our children (A televisão na vida de nossas crianças). 3. ed. Stanford: Stanford University Press, 1968. 
De acordo com um balanço de pesquisa sobre televisão e criança na América Latina, realizado por Guillermo Orozco Gómez, a corrente que mais proliferou em estudos sobre os efeitos da mídia centrava-se nos efeitos educacionais da programação não educativa. "Tinha como pressuposto básico que a educação das crianças era influenciada mais fortemente pela programação regular das emissoras do que por programas especificamente educacionais"'ll.

Se a criança aprende com programas que priorizam a diversão, por que os programas educativos não podem ser divertidos? Por que não fazê-los divertidos? Por que não usar essa atração para atender às necessidades cognitivas $\mathrm{e}$ emocionais da criança? Por que não usar essa atração para promover uma aproximação entre a criança e os conhecimentos escolares? Por que não abrir a concepção de programa pedagógico para o mundo da referência da cultura popular de massa, incorporando subjetividades, ambigüidades, desejos e emoções do público infantil?

\section{VILA SÉSAMO'12, O PRIMEIRO EXEMPLO}

Criado em 1969, nos Estados Unidos, Vila Sésamo (Sesame Street) foi o primeiro programa infantil de televisão a ensinar conceitos e divertir. A estrutura era formada por quadros ou módulos de curta duração. Repetiam-se em ritmo acelerado. Cada módulo tinha objetivo pedagógico específico e formato inspirado em técnicas publicitárias.

Tornou-se uma referência cultural mundializada de série infantil educativa de televisão. Seus princípios constituem indicações observadas por produtores e realizadores de programas educativos inovadores. Mas, muitos críticos afirmam que sua limitação foi ter considerado o entretenimento de modo superficial, esvaziado de emoções.

No reexame de Vila Sésamo, Michèle Mattelart situou-o no contexto histórico dos anos 60 , como fruto de uma certa utopia democrática. Reconheceu-o como matriz simbólica, o primeiro empreendimento educacional a relacionar educação, tecnologia audiovisual e cultura de massa. Atribuiu-lhe ênfase no aspecto cognitivo, nas operações mentais, na aprendizagem útil, em detrimento do aspecto emocional como decorrente das pressões das instituições de avaliação ${ }^{13}$.

Apesar do sucesso em integrar diversão e educação, as críticas ideológicas foram implacáveis. Vila Sésamo foi "hostilizado como agente do imperialismo pela esquerda latino-americana, nas décadas de 60 e 70"14.

Para Raymond Williams, Vila Sésamo captou o prazer das crianças com jingles e publicidade. Usou esse divertimento num sentido não comercial, mas educativo, como motivação para ensinar conceitos. $\mathrm{O}$ autor afirmou ser um "abuso de termos" chamar esse método de comercial. Constatou que a

11. OROZCO GÓMEZ, G. et al. A televisão e as crianças. Comunicação \& Educação. São Paulo: CCA-ECA-USP/Moderna, n. 7, set./dez. 1996. p. 52.

12. A versão brasileira de Sesame Street foi adaptada pela TV Cultura em parceria com Children's Television Workshop e TV Globo. Teve 150 programas, de 55 minutos cada. Foi veiculado de out. 1972 a mar. 1977, com índices de audiência média entre 15 a 20 pontos.

13. MATTELART, M. Education, television and mass culture: reflections on research into innovation (Educação, televisão e cultura de massa: reflexões sobre pesquisas em inovação). In: DRUMMOND, P., PATERSON, R. (orgs.). Television in transition (Televisão em transição). London: Bristh Film Institute, 1986. p. 164-184.

14. SILVA, C. E. L. Nos Estados Unidos Vila Sésamo faz 25 anos... Folha de S. Paulo, 30 ago. 1993. 
resposta educativa desejada pelos produtores de Vila Sésamo - priorizando as crianças pobres de áreas urbanas - foi conseguida ${ }^{15}$.

\section{CASTELO RÁ-TIM-BUM: EDUCAÇÃO E ENTRETENIMENTO}

O programa Castelo Rá-Tim-Bum ${ }^{16}$, produzido pela TV Cultura de São Paulo, em 1994, não se enquadra no modelo clássico de programa educativo. Sua estrutura é tecida pelo reencontro da intenção pedagógica com matrizes culturais, formatos industriais, padrões comerciais. Constitui-se em entretenimento educativo ${ }^{17}$.

O Castelo Rá-Tim-Bum preocupa-se em atrair o público. Usa como entretenimento a ancestral atração humana pela narrativa, pelo gosto de contar histórias. Junto a esse mundo de fantasia traz ensinamentos de vida e o aporte da "temporalidade de longa duração" que se verifica nas novelas ${ }^{18}$.

O Castelo Rá-Tim-Bum incorpora elementos de sucesso comprovados em programas infantis que se empenharam em educar e conquistar público.

Inspirado em Vila Sésamo e Rá-Tim$B u m^{19}$, possui quadros pedagógicos que oferecem variadas situações de aprendizagem, em diversos formatos narrativos. Como $\mathrm{Si}^{-}$ tio do Pica-Pau Amarelo 20 e Mundo da $L u a^{21}$, apresenta narrativa com base dramática. Recria o uso dessa narrativa como fio para enlaçar os quadros pedagógicos.

O racional versus o emocional começa a ser superado na premissa. A necessidade dramática do herói Nino, de 300 anos, fundamenta-se na falta da escola. Toda sua busca se volta para superar a lacuna da falta de amigos e de conhecimentos. O herói precisa de amigos para conhecer a si e ao mundo. Nos 13 episódios analisados, os fatos que dão origem às intrigas podem estar ligados à racionalidade ou à afetividade. Constata-se que as articulações entre quadros pedagógicos e fio narrativo seguem a lógica da narrativa, as necessidades das histórias. Não há subordinação aos propósitos de uma explicação didática. Aproxima-se de uma articulação semelhante àquela dos núcleos de uma telenovela. $O$ processo narrativo é tipicamente televisual, não-linear. Múltiplas linhas se imbricam, harmonizam-se e criam uma única linha dramática.

Os mundos característicos do modelo clássico, mundo mundano, mundo da sala de aula e mundo do especialista, estudados por Jacquinot ${ }^{22}$ persistem. São porém transformados, diluídos, permeados pelo novo mundo: a fantasia, o imaginário. Verifica-se a presença do mundo mundano pelas crian-

15. WILLIAMS, R. Sesame Street (Vila Sésamo). In: O'CONNOR, A. (ed.). Raymond Williams on television: selected writings (Raymond Williams: seleção de escritos sobre televisão). London: Routledge, 1989. p. 158-160.

16. Castelo Rá-Tim-Bum: produção da TV Cultura de São Paulo. No ar desde 9 de maio de 1994. Número de 90 episódios de 25 min. Direção: Cao Hamburger. Idéia original: Cao Hamburger, Flávio de Souza. Consultoria pedagógica: Zélia Cavalcanti Lima. Sobre o programa: MUYLAERT, R. As funções da Televisão Educativa. (Entrevista.) Comunicação \& Educação. São Paulo: CCA-ECA-USP/Moderna, n. 2, jan./abr. 1995. p. 76-87.

17. CARNEIRO, V. L. Q. O educativo... op. cit.

18. Sobre essa relação: MATTELART, A. e MATTELART, M. O carnaval das imagens: a ficção na TV. São Paulo: Brasiliense, 1989.

19. Rá-Tim-Bum: produção da TV Cultura, 1990. Número de 190 episódios de 30 min. Direção: Fernando Meireles. Autores: Flávio de Souza, Cláudia Dalla Verde e Tacus. Coordenação pedagógica: Célia Marques.

20. Sítio do Pica-Pau Amarelo: produção da TV Educativa-Rio e TV Globo, veiculado de 1977 a 1988 . Número de 150 episódios de 55min. Adaptação: Benedito Ruy Barbosa. Direção: Geraldo Casé

21. Mundo da Lua: produção da TV Cultura, 1991. Número de 52 episódios de 30 min. Idéia original: Flávio de Souza.

22. JACQUINOT, G. Image... op. cit. 
ças que freqüentam o Castelo, pelos prédios em sua volta, pelas demandas e emoções do mundo real. Dentro desse mundo mundano situa-se o Castelo, representando o mundo fantástico com criança de 300 anos, gato, cobra, um par de botas que fala, bruxa, fadas. A fantasia atende às solicitações centradas no aprender. O livro, objeto característi- co do mundo escolar, faz-se presente de diversas formas, em diferentes momentos. Há especialistas em diversas áreas do conhecimento: história universal, ciências, matemática, ecologia. A maior especialista, uma feiticeira de 6 mil anos, mantém relações de proximidade e contemporaneidade com personagens históricas.

Figura 1 - Os quatro mundos de referência do Castelo Rá-Tim-Bum

\section{MUNDO MUNDANO}

Transforma-se pelas relações equilibradas com o mundo fantástico.

\section{MUNDO DA SALA DE AULA}

É desenfatizado.

Refere-se às crianças que freqüentam escola; refere-se ao desejo do herói de ir para a escola; refere-se a objetos que lembram escola.

\section{MUNDO DO ESPECIALISTA}

O conhecimento especializado é tomado como um conhecimento não especializado, por meio de sua imbricação com os problemas da vida.

\section{MUNDO FANTÁSTICO}

Permeia os outros três mundos, fazendo com o mundo real um jogo de apoio mútuo

$\Downarrow$ direção ação narrativa

Não se verificam fronteiras entre o mundo mundano, o do especialista e o da escola. Trata-se de outro esquema de articulação entre os mundos, como sugere a Figura 1. Observa-se uma dissolução de fronteiras entre os mundos, através do mundo fantástico. E, em lugar de rupturas de um mundo para outro, todos fazem fluir a narrativa. Simultaneamente, o processo narrativo faz avançar o educativo. A ruptura é integra$\mathrm{da}$ ao processo narrativo.

Para um entrevistado (10 anos), o Castelo Rá-Tim-Bum era mais que um programa educativo, mais que um entretenimento, era uma morada: " $O$ Castelo é a vida deles, $e ́$ onde eles moram; porque, se não existisse o Castelo, onde eles iam morar?"23.

O programa Castelo Rá-Tim-Bum rompe com a concepção hegemônica de programa educativo como "gênero escolar”, que pressupõe público cativo e mediação na sala de aula. Mostra a possibilidade de mediar pedagogicamente a produção em televisão por meio da inscrição da intencionalidade em diversos formatos de televisão. Desmente a incompatibilidade de convivência da finalidade educativa com as linguagens, o timing e o interesse maior da televisão: a audiência. 
Por fim, faz crer na possibilidade de o artigo 76 do Estatuto da Criança e do Adolescente ser aplicado não como simples instrumento de censura para coibir abusos e desrespeitos ao público infanto-juvenil,

Resumo: O artigo trata da reflexāo sobre a possibilidade de articulação entre a intencionalidade educativa e os formatos de narrativa ficcional de televisão na programação infantil. Discute o modelo clássico de estruturação de programa educativo em função de uma intenção didática. Reexamina o modelo educativo proposto por Vila Sésamo, criado nos EUA, e analisa o programa Castelo Rá-TimBum, da TV Cultura de São Paulo, como superação do conceito clássico. Conclui pela viabilidade de se adequar o educativo à linguagem televisual e narrativa.

Palavras-chave: programa educativo, televisão, entretenimento, Castelo Rá-Tim-Bum, Vila Sésamo mas de garantia de uma oferta ampla, variada e diversificada de programas que atendam às necessidades de desenvolvimento intelectual, emocional e social de crianças e adolescentes.

Abstracts: The article deals with the reflection on the possibility of articulation between educative intentionality and the forms of fictional narrative in television in programming for children. It discusses the classical model of educative program structuring as a function of a didactic intention. The article reexamines the educational model proposed by Sesame Street, created in the USA and analyzes the TV Cultura (São Paulo) program Castelo Rá-Tim-Bum, as having surpassed the classical concept. It concludes that it is viable to adopt educative aspects to the television language and narrative.

Key words: educative program, television, entertainment, Castelo Rá-Tim-Bum, Sesame Street 